\title{
Chiral vanadyl salen catalyst immobilized on mesoporous silica as support for asymmetric oxidation of sulfides to sulfoxides
}

\author{
T. Ben Zid $\cdot$ I. Khedher $\cdot$ A. Ghorbel
}

Received: 21 October 2009/Accepted: 19 February 2010/Published online: 16 March 2010

(C) The Author(s) 2010. This article is published with open access at Springerlink.com

\begin{abstract}
The chiral vanadyl salen complex was immobilized into mesoporous silica by a covalent grafting method using 3-aminopropyltriethoxysilane as a reactive surface modifier. The formation and integrity of the complex have been confirmed by FT-IR, $\mathrm{UV}$-vis and BET measurements and the complex was tested in the asymmetric oxidation of sulfide to sulfoxide using $\mathrm{H}_{2} \mathrm{O}_{2}$ as oxidant. The immobilized complex showed better catalytic activity than the neat complex, while the neat complex has deactivated in the reaction. The combination of the heterogenized catalyst, $\mathrm{H}_{2} \mathrm{O}_{2}$ and $\mathrm{CH}_{2} \mathrm{Cl}_{2}$ as solvent offers a selective catalytic system for oxidation of sulfide to sulfoxide with a low but significant enantioselectivity in the range of $8-10 \%$ ee. In addition, the heterogenized catalyst could be easily separated from the products and reused.
\end{abstract}

Keywords Vanadyl salen complexes - Asymmetric oxydation of sulfides · Heterogeneous catalysis - Mesoporous silica as support

\section{Introduction}

Asymmetric metal catalysis is in the focus of current chemical research, and several major breakthroughs have been achieved in recent years [1-3]. In this field, the development of chiral Schiff base ligands received considerable interest since Jacobsen's work [4]. It was shown that the Schiff base ligands are able to coordinate many different metals, and to stabilize them in various oxidation states, enabling the use of Schiff base metal complexes for a large variety of useful catalytic transformations such as asymmetric epoxidation [5-8], asymmetric sulfide oxidation [9, 10], cyclopropanation [11], aziridination [12], Knoevenagel condensation [13], and

T. Ben Zid · I. Khedher $(\bowtie) \cdot$ A. Ghorbel

Département de Chimie, Faculté des Sciences de Tunis,

Laboratoire de Chimie des Matériaux et Catalyse, 1060 Tunis, Tunisie

e-mail: ilyeskhadher@yahoo.com 
selective hydrogenation reactions under homogenous conditions $[14,15]$. Due to the advantages of heterogeneous catalysis systems, namely easy catalyst/product separation and simple catalyst recycling, the heterogenization of these homogenous chiral catalysts onto several supports has received great attention in recent years [16-22]. In spite of this, the use of the chiral vanadium salen Schiff base immobilized on inorganic support as asymmetric oxidation catalysts has been rather scarce and has mainly focused on the asymmetric addition of trimethylsilyl cyanide to aldehydes [23]. In the present study, we describe the preparation and characterization of the $\mathrm{VO}$ (salen) complex immobilized on mesoporous silica and its application as a heterogeneous catalyst in the asymmetric oxidation of sulfide to sulfoxide.

\section{Experimental}

\section{Characterization methods}

Fourier Transform Infrared (FT-IR) spectra were recorded in the $400-4,000 \mathrm{~cm}^{-1}$ spectral region based on a Perkin-Elmer FTIR paragon 1000 PC spectrometer by dispersing the materials in $\mathrm{KBr}$ discs. UV-visible reflectance spectra were obtained at room temperature by means of a Perkin-Elmer Lamda 8 spectrometer using $\mathrm{BaSO}_{4}$ as reference. Elemental analysis $(\mathrm{C}, \mathrm{H}, \mathrm{N})$ of organic compounds were carried out on a Perkin-Elmer analyzer. Vanadium loading was measured by atomic absorption spectrometry on a Perkin-Elmer 3100 apparatus, after sample dissolution through acid attack. BET surface area was determined using $\mathrm{N}_{2}$ sorption data measured at $77 \mathrm{~K}$ by means of a Micrometrics ASAP 2000 apparatus. The pore diameter of the samples was determined from the desorption branch of $\mathrm{N}_{2}$ adsorption isotherm using the BJH method.

\section{Catalytic test}

The catalytic properties of catalysts were tested in the asymmetric oxidation of sulfide to sulfoxide, which was performed by stirring the catalyst (a quantity containing $0.2 \mathrm{mmol}$ as $\mathrm{V}$ ) in the presence of sulfide $(248 \mathrm{mg}, 2 \mathrm{mmol})$ in dry solvent $(10 \mathrm{~mL})$ under inert atmosphere, followed by the dropwise addition (for a period of $10 \mathrm{~min}$ ) of $4 \mathrm{mmol}$ of oxidant ( $33 \mathrm{wt} \% \mathrm{H}_{2} \mathrm{O}_{2}$ aq.). The reaction was monitored by GC-FID analysis on a TRACE GC Ultra, using helium carrier gas, equipped with $\mathrm{SPB}^{\mathrm{TM}}-5$ Capillary column $(30 \mathrm{~m} \times 0.25 \mathrm{~mm} \times 0.25 \mu \mathrm{m}$ film thickness). The enantiomeric excess was determined with pure sulfoxide by ${ }^{1} \mathrm{H}$ NMR $(300 \mathrm{MHz})$ in the presence of one equivalent of chiral shift reagent (S)-N-(3,5 dinitrobenzoyl)- $\alpha$-phenylamine in $\mathrm{CDCl}_{3}$ [24].

\section{Synthesis}

The chiral vanadyl salen complex was immobilized onto mesoporous silica (silica gel from ALFA-AESER, $300 \mathrm{~m}^{2} \mathrm{~g}^{-1}$ ) by multi-grafting method according to the procedure shown in Scheme 1. In addition, the homogenous VO(salen) complex of 
the similar structure to the immobilized one was synthesized following the method described by Zamian et al. [25] and used as a reference to prove the complex immobilization and to compare the catalytic activity. The synthetic procedure for the homogenous complex is also shown in Scheme 2.

\section{Immobilization of chiral vanadyl salen complex on mesoporous silica}

A suspension of (3-aminopropyl) triethoxysilane (443 $\mathrm{mg}, 2 \mathrm{mmol}$ ) and $2 \mathrm{~g}$ of silica gel in $15 \mathrm{~mL}$ of toluene was heated under reflux with stirring under nitrogen atmosphere. After heating for $24 \mathrm{~h}$, the powder (sample 3) was filtered, washed with diethylether and dried under vacuum at $40{ }^{\circ} \mathrm{C}$. The density of aminopropyl groups

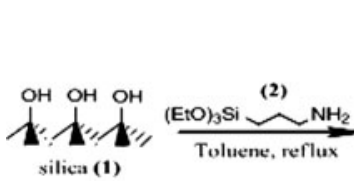

silica (1)

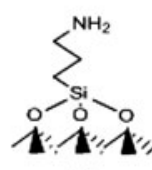

(3)
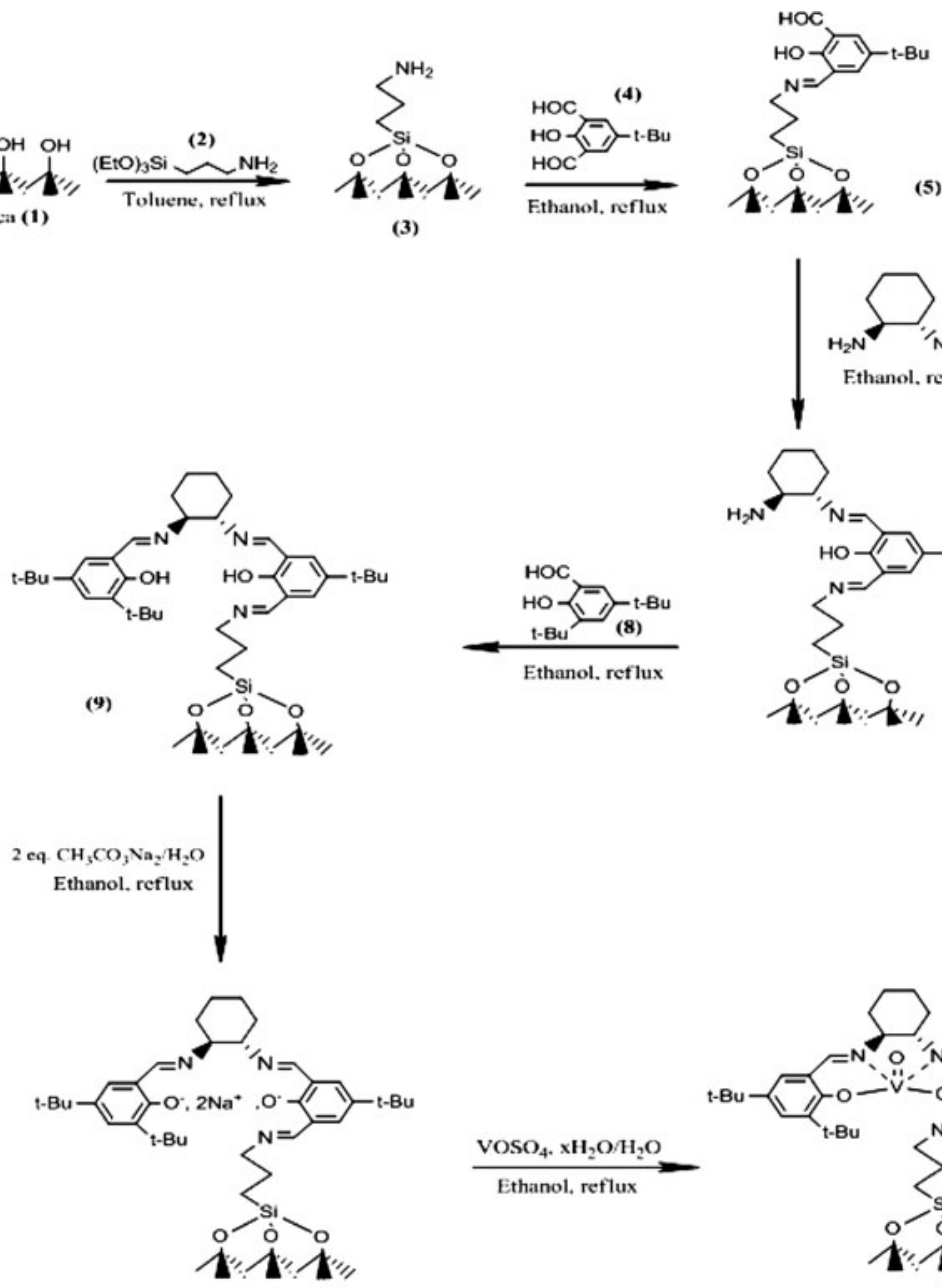

(10)

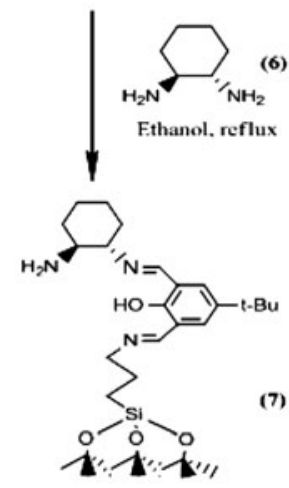

(6)

(7)

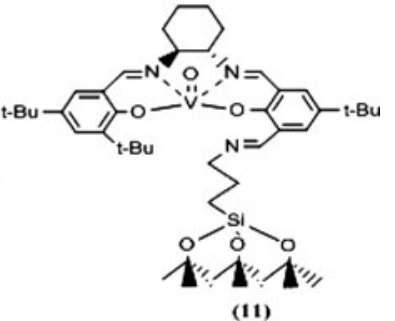

Scheme 1 The procedure for the synthesis of VO(salen) complex immobilized on mesoporous silica ( $\mathrm{Si}-$ $\mathrm{VO}($ salen)) 


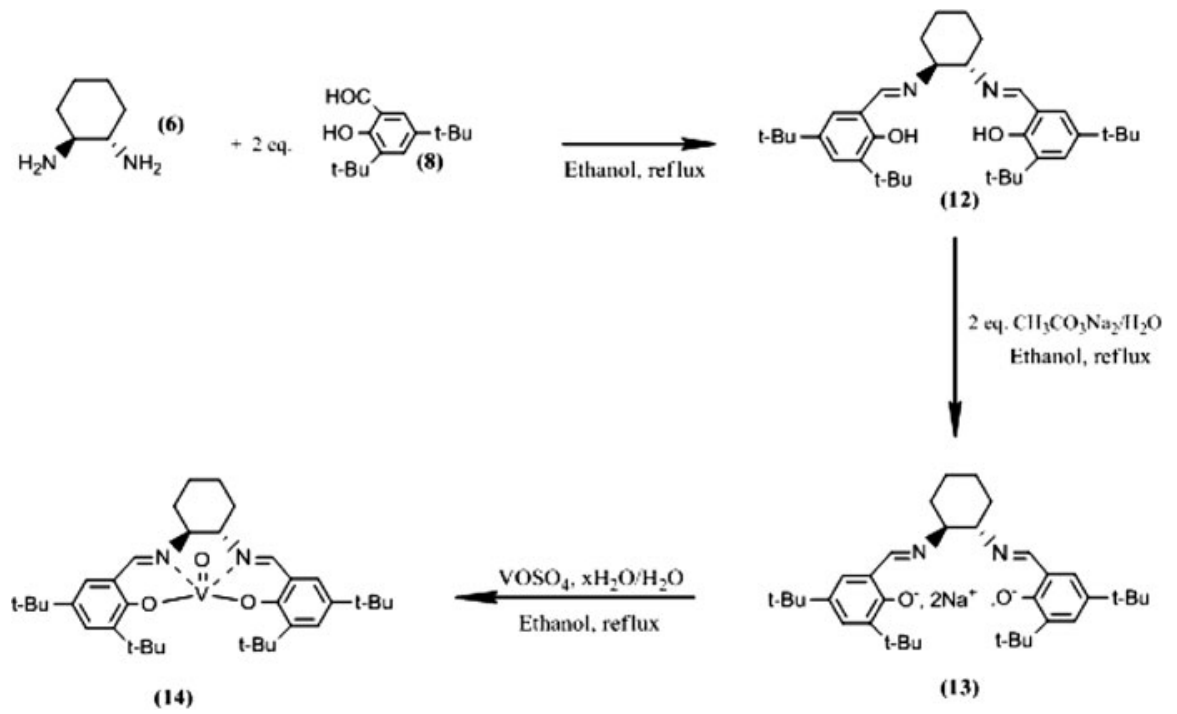

Scheme 2 The procedure for the synthesis of $\mathrm{VO}$ (salen) complex

anchored in the silica was estimated from combustion chemical analysis with $0.95 \mathrm{mmol}$ of $\mathbf{2}$ was immobilized on $1 \mathrm{~g}$ of $\mathbf{1}$.

Diformylphenol (2,6-diformyl-4-tert-butylphenol) was reacted with the previously obtained 3-aminopropylsilyl functionalised silica with excess amount in a refluxing ethanol solution for $10 \mathrm{~h}$. One aldehyde group in the diformylphenol derivative reacts with the amino group of 3-aminopropylsilane immobilized on silica. After cooling, the powder was collected by filtration, washed with diethylether and methanol. The condensation of the remaining aldehyde group with one amino group in the chiral auxiliary $(1 R, 2 R)-(-)-1,2$-diaminocyclohexane (with excess) has occurred and the subsequent condensation of the other amino group in diaminocyclohexane with the excess corresponding salicylaldehyde derivatives (2,4-di-tert-butyl salicylaldehyde) in refluxing ethanol has resulted in the formation of chiral salen ligand on silica as shown in Scheme 1. The VO(salen) complex immobilized on silica was accomplished through the synthetic sequence given in Scheme 1 as follows: the immobilized chiral salen ligand 9 was reacted with 2.0 equivalent of sodium acetate $(156 \mathrm{mg}, 1.9 \mathrm{mmol})$ under reflux for $30 \mathrm{~min}$ using ethanol/water as solvent. 1.0 equivalent of $\mathrm{VOSO}_{4} \cdot x \mathrm{H}_{2} \mathrm{O}(155 \mathrm{mg}, 0.95 \mathrm{mmol})$ was added to the resulting solution. The final mixture was refluxed again for $5 \mathrm{~h}$. After cooling, the heterogeneous $\mathrm{VO}$ (salen) complex 11 was recovered by filtration, washed several times with water and ethanol and dried under vacuum at $40{ }^{\circ} \mathrm{C}$ to give a green solid. The vanadium content in $\mathrm{Si}-\mathrm{VO}($ Salen) was estimated to be $4.5 \mathrm{wt} \%$ by atomic absorption spectrometry.

\section{Synthesis of homogeneous $\mathrm{VO}($ salen) complex}

The chiral salen ligand 12 was formed by condensing the diamine $(1 R, 2 R)-(-)-1,2-$ diaminocyclohexane $(114.2 \mathrm{mg}, 1 \mathrm{mmol})$ with 2,4-di-tert-butyl salicylaldehyde 
(469 mg, $2 \mathrm{mmol}$ ) in a 1:2 ratio in ethanol. The mixture was heated to reflux with stirring under nitrogen atmosphere for $24 \mathrm{~h}$. The resulting yellow solid was isolated by filtration, recrystallized from ethanol and dried under vacuum at ambient temperature. Anal. Calcd. for $\mathrm{C}_{36} \mathrm{H}_{54} \mathrm{~N}_{2} \mathrm{O}_{2}$ : C, 79.07; H, 9.95; N, 5.12\%. Found: $\mathrm{C}$, 79.13; H, 9.98; N, 5.16\%. ${ }^{1} \mathrm{H}$ NMR ( $\left.\mathrm{CDCl}_{3} / \mathrm{TMS}, 300 \mathrm{MHz}\right): \delta \mathrm{ppm} 13.76$ (s, 2H); $8.34(\mathrm{~s}, 2 \mathrm{H}) ; 7.34(\mathrm{~d}, 2.2 \mathrm{~Hz}, 2 \mathrm{H}) ; 7.02(\mathrm{~d}, \mathrm{~J}=2.2 \mathrm{~Hz}, 2 \mathrm{H}) ; 3.7-3.31(\mathrm{~m}, 2 \mathrm{H}) ; 2.0$ $1.4(\mathrm{~m}, 6 \mathrm{H}) ; 1.45(\mathrm{~s}, 20 \mathrm{H}) ; 1.27(\mathrm{~s}, 18 \mathrm{H}) .{ }^{13} \mathrm{C} \mathrm{NMR}\left(\mathrm{CDCl}_{3} / \mathrm{TMS}, 300 \mathrm{MHz}\right): \delta$ ppm 166, 158, 140, 137, 126.5, 126, 118, 72, 35, 34.2, 33.5, 29.3, 24.6.

As shown in Scheme 2, the synthesis of VO(salen) complex 14 was carried out using a solution of $\mathrm{VOSO}_{4} \cdot x \mathrm{H}_{2} \mathrm{O}$ as a precursor. Thus, $2 \mathrm{mmol}(164 \mathrm{mg})$ of sodium acetate was added to a hot ethanol solution containing $0.546 \mathrm{~g}(1 \mathrm{mmol})$ of the chiral salen ligand. The mixture was heated to reflux with stirring for $30 \mathrm{~min}$. After that, a solution of $1 \mathrm{mmol}(163 \mathrm{mg})$ oxovanadium(IV) sulfate hydrate $\left(\mathrm{VOSO}_{4} \cdot x \mathrm{H}_{2} \mathrm{O}\right)$ in $10 \mathrm{~mL}$ of distilled water was added. A green precipitate was formed almost immediately; the mixture was refluxed with stirring for $4 \mathrm{~h}$. After cooling slowly to room temperature, the reaction mixture was held at $0{ }^{\circ} \mathrm{C}$ for $12 \mathrm{~h}$ (Scheme 2). The resulting precipitate was collected by filtration, washed twice with $20 \mathrm{~mL}$ of distilled water and twice with $10 \mathrm{~mL}$ of ethanol and dried over silica in a desiccator in vacuo at room temperature for $72 \mathrm{~h}$ to give a green solid. Anal. Calcd. for $\mathrm{C}_{36} \mathrm{H}_{52} \mathrm{VN}_{2} \mathrm{O}_{3}: \mathrm{C}$, 70.7; H, 8.51; N, 4.58; V, 8.34\%. Found: C, 71.1; H, 8.70; N, 4.62; V, 8.47\%.

\section{Results and discussion}

Homogeneous catalyst characterization

The IR spectra of the free ligand and the $\mathrm{VO}($ salen) complex present various bands in the region $400-4,000 \mathrm{~cm}^{-1}$ (Fig. 1). The $\mathrm{O}-\mathrm{H}$ stretching frequency of the free ligand is expected in the region $3,300-3,800 \mathrm{~cm}^{-1}$. However, the $\mathrm{O}-\mathrm{H}$ stretching frequency is shifted to around $2,589 \mathrm{~cm}^{-1}$ due to the internal hydrogen bridge $\mathrm{OH}-$ $\mathrm{N}=\mathrm{C}[26,27]$. The $\mathrm{C}=\mathrm{N}$ stretching frequency at $1,634 \mathrm{~cm}^{-1}$ is in the region 1,590 $1,640 \mathrm{~cm}^{-1}$ reported for similar ligands $[28,29]$. The $\mathrm{C}-\mathrm{N}$ stretching frequency is reported in the region $1,350-1,410 \mathrm{~cm}^{-1}$ [30]. For the free ligand, this band was observed as a medium band at $1,390 \mathrm{~cm}^{-1}$. A fourth characteristic band due to the $\mathrm{C}=\mathrm{C}$ stretching frequency appears as a strong band at $1,600 \mathrm{~cm}^{-1}$.

The characteristic $\mathrm{V}=\mathrm{O}$ stretching frequency in the $\mathrm{VO}($ salen) complex appears at $980 \mathrm{~cm}^{-1}$, within the range $970-997 \mathrm{~cm}^{-1}$ reported for similar oxovanadium (IV) complexes $[31,32]$. The $\mathrm{O}-\mathrm{H}$ stretching frequency of the free ligand at $2,589 \mathrm{~cm}^{-1}$ is absent, as expected, in the spectrum of the coordinated ligand, confirming the assignment to a hydrogen bridge. On coordination of the Schiff base ligand, the $\mathrm{C}=\mathrm{N}$ stretching frequency is shifted to lower frequency, $1,535 \mathrm{~cm}^{-1}$, indicating a decrease in the $\mathrm{C}=\mathrm{N}$ bond order due to coordination of vanadium with azomethine nitrogen lone pair [23]. This effect is supported by the presence of a new absorption peak at $561 \mathrm{~cm}^{-1}$ attributed to the V-N stretching frequency, which was not found in the spectrum of the free ligand [25]. 


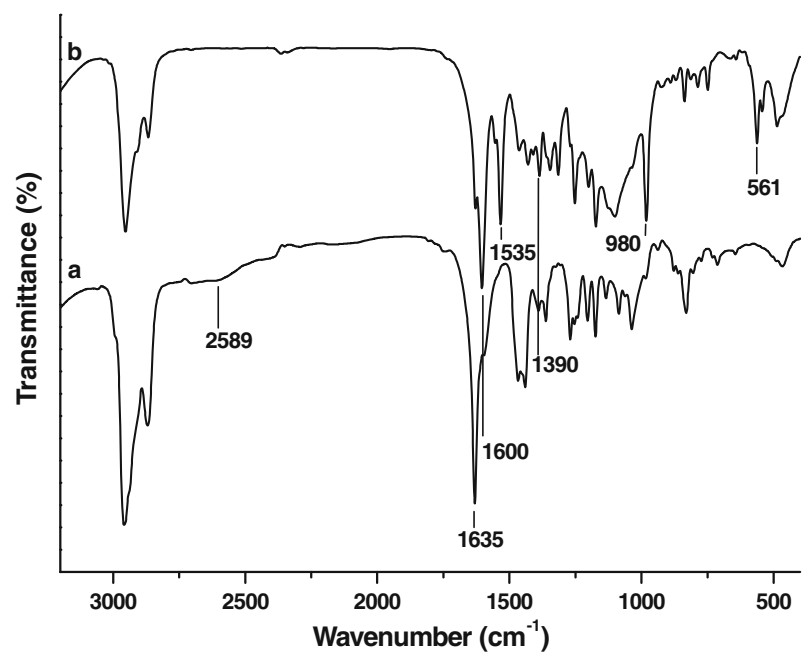

Fig. 1 IR spectra of (a) chiral salen ligand (sample 12) and (b) VO(salen) complex (sample 14)

The synthesis of the chiral salen ligand and its coordination to vanadyl group $\mathrm{V}=\mathrm{O}$ can be assessed by UV-vis spectroscopy (Fig. 2). Thus, in the diffuse reflectance UV-visible spectrum of chiral salen ligand display four main bands at around 256, 316, 327 and $342 \mathrm{~nm}$ (curve a). These are the characteristic bands for salen type Schiff base ligands due to $\mathrm{n}-\pi^{*}$ and $\pi-\pi^{*}$ transitions. Moreover, it is thought that the absorbance peak at around $256 \mathrm{~nm}$ is due to the imine $(\mathrm{C}=\mathrm{N})$ group of the ligand [33].

As significant differences were observed in the $\mathrm{VO}$ (salen) complex UV-vis spectrum in comparison to chiral salen ligand spectrum, appearance of three new bands at around 360, 390 and $412 \mathrm{~nm}$ was detected. These bands could be the superposition of the charge-transfer transitions between the ligand and the central vanadium atoms [34] and $n-\pi^{*}$ and $\pi-\pi^{*}$ transitions which were displaced to a lower frequency by coordination of nitrogen atoms with vanadyl groups. Moreover, the absorption band of $\mathrm{C}=\mathrm{N}$ group appears in the range 360-370 nm reported for similar metal complexes $[35,36]$. In addition, a broad band at $630 \mathrm{~nm}$ was observed which is attributed to V(IV) $\mathrm{d}-\mathrm{d}$ transition [37].

\section{Heterogeneous catalyst characterization}

The multi-step grafting method used to immobilize the unsymmetrical chiral complex onto silica was assessed by IR (Figs. 3, 4). Compared to pure silica, the aminopropylsilyl-functionalized silica (Fig. 3, curve b) gives a new band at $1,570 \mathrm{~cm}^{-1}$ which can be attributed to the deformation vibration of $\mathrm{N}-\mathrm{H}$ band of the amine group with three C-H stretchings at 2960, 2930 and $2855 \mathrm{~cm}^{-1}$ due to the alkyl groups (aminopropyl group). The reaction of 2,6-diformyl-4-tert-butylphenol with 3aminopropylsilyl-functionalized silica (Fig. 3, curve c) shows the disappearance of the band at $1,570 \mathrm{~cm}^{-1}$ indicating the condensation of the amino group with one aldehyde group in 2,6-diformyl-4-tert-butylphenol to give a new band at $1,640 \mathrm{~cm}^{-1}$ 


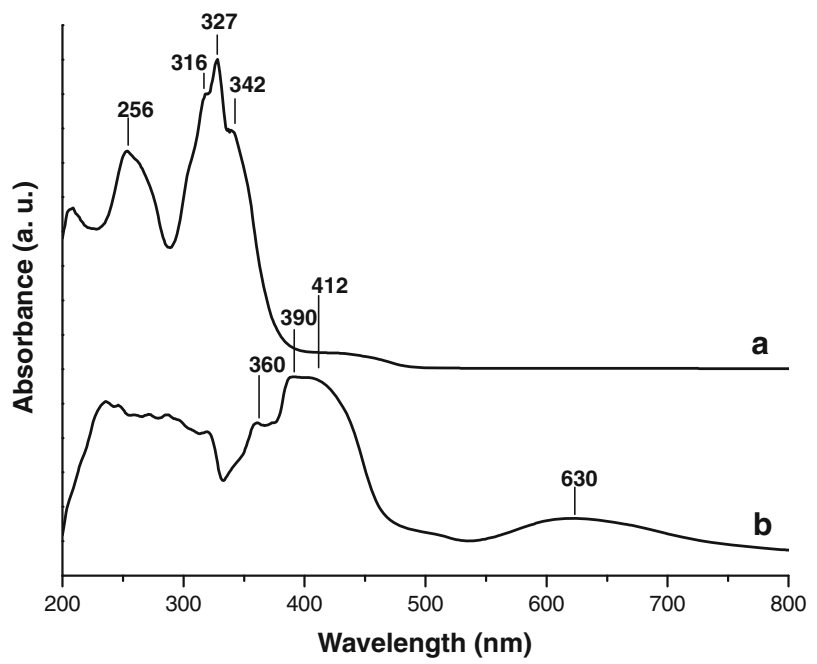

Fig. 2 UV-vis spectra of (a) chiral salen ligand (sample 12) and (b) VO(salen) complex (sample 14)

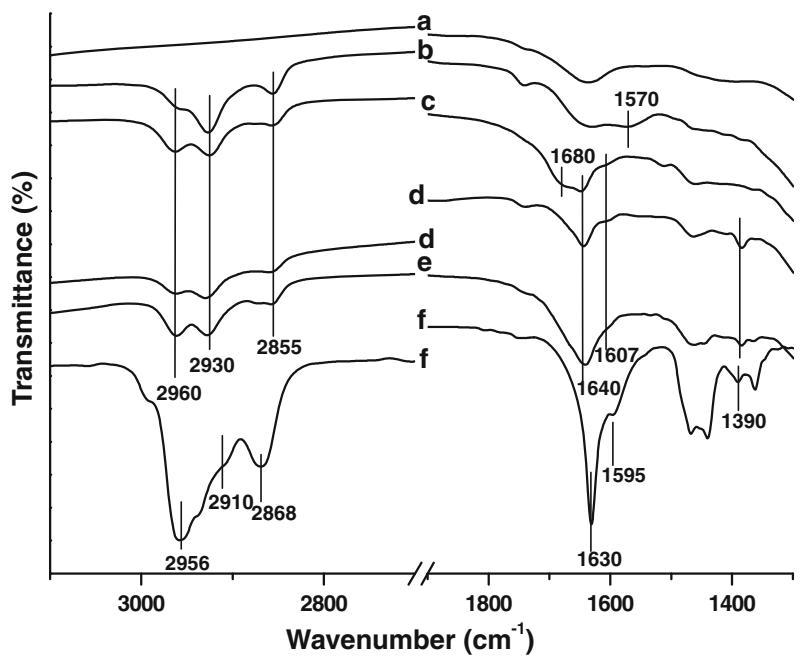

Fig. 3 IR spectra of $(a)$ pure silica, $(b)$ aminopropyl modified silica (sample 3), $(c)$ sample 3, $(d)$ chiral half unit of salen immobilized on silica (sample 5), $(e)$ chiral salen ligand immobilized on silica (sample 7) and $(f)$ chiral salen ligand

assigned to the stretching vibration of the $\mathrm{C}=\mathrm{N}$ bond (imine bond). Two other new bands appear at 1,680 and 1,607 $\mathrm{cm}^{-1}$ which are due to the remaining aldehyde $\mathrm{C}=\mathrm{O}$ group and the stretching vibration of $\mathrm{C}=\mathrm{C}$ bonds of the phenyl ring, respectively.

The presence of the chiral half unit of salen anchored on silica can be shown (Fig. 3, curve d) by the disappearance of the band at $1,680 \mathrm{~cm}^{-1}$ due to the subsequent condensation of the remaining aldehyde $\mathrm{C}=\mathrm{O}$ group with one amino 
group in the $(1 R, 2 R)-(-)-1,2$-diaminocyclohexane chiral auxiliary. This is supported by the increase of the intensity of the band assigned to the stretching vibration of the $\mathrm{C}=\mathrm{N}$ bond and the appearance of a new band at $1,390 \mathrm{~cm}^{-1}$ due to $\mathrm{C}-\mathrm{N}$ stretching frequency.

The comparison of the spectra of the free chiral salen ligand and sample 7 showed evidence of the immobilization of the chiral salen ligand over the support (Fig. 3, curves e and f), since the three most characteristic bands of the free chiral salen ligand appeared in IR spectrum of silica supported chiral salen ligand. These bands are attributed to $\mathrm{C}-\mathrm{N}$ stretching frequency at $1,390 \mathrm{~cm}^{-1}$ and to the stretching vibrations of $\mathrm{C}=\mathrm{N}$ and $\mathrm{C}=\mathrm{C}$ bonds which are slightly shifted from 1,630 and $1,595 \mathrm{~cm}^{-1}$ to 1,640 and $1,607 \mathrm{~cm}^{-1}$, respectively, for the immobilized chiral salen ligand.

On coordination of the immobilized chiral salen ligand to the vanadyl group, the characteristic bands of the metal salen complex appearing at 1535, 980 and $561 \mathrm{~cm}^{-1}$ are assigned to the stretching frequency of $\mathrm{C}=\mathrm{N}, \mathrm{V}=\mathrm{O}$ and $\mathrm{V}-\mathrm{N}$ bands, respectively (Fig. 4). These bands are absent in the free and immobilized chiral salen ligand (Fig. 4, curve c) but can be clearly observed for the $\mathrm{VO}$ (salen) complexes either free (Fig. 4, curve a) or anchored on the silica (Fig. 4, curve b).

The solid reflectance UV-vis spectrum (Fig. 5) also supported successful coordination of the immobilized salen ligand with the vanadyl group, since the spectrum of the $\mathrm{VO}$ (salen) complex supported on silica (curve b) is similar to that of the homogeneous complex (curve a). The characteristic charge transfer bands of homogenous $\mathrm{VO}$ (salen) complex are present in the immobilized complex spectrum, but the bands are slightly shifted from 360,390 and $412 \mathrm{~nm}$ to 368,394 and $417 \mathrm{~nm}$, in order. The $\mathrm{d}-\mathrm{d}$ transition band near $630 \mathrm{~nm}$ was also observed in the immobilized complex spectrum though with a lower resolution than that for the transmission spectrum of homogenous $\mathrm{VO}$ (salen) complex.

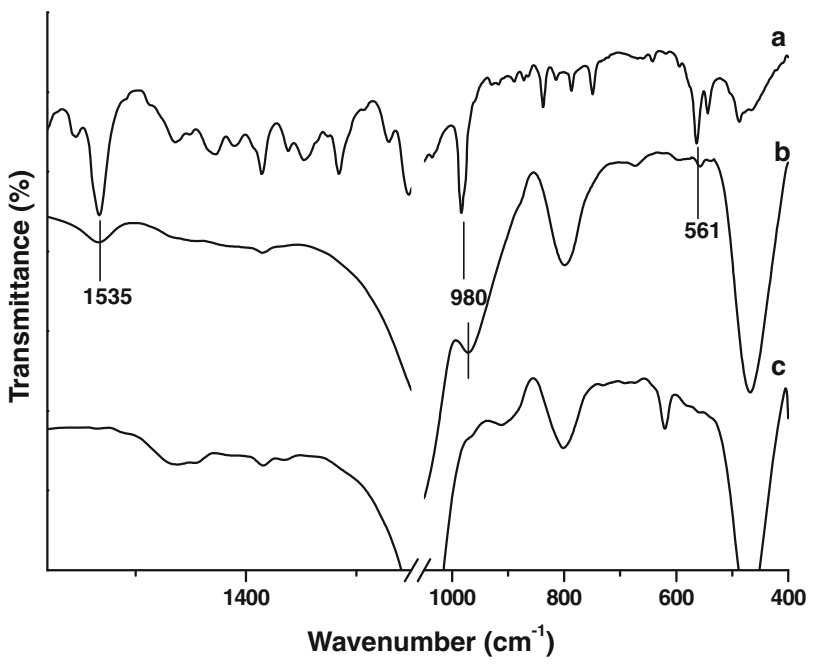

Fig. 4 IR spectra of (a) VO(salen) complex (sample 14), (b) Si-VO(salen) (sample 11) and (c) chiral salen ligand immobilized on silica (sample 7) 


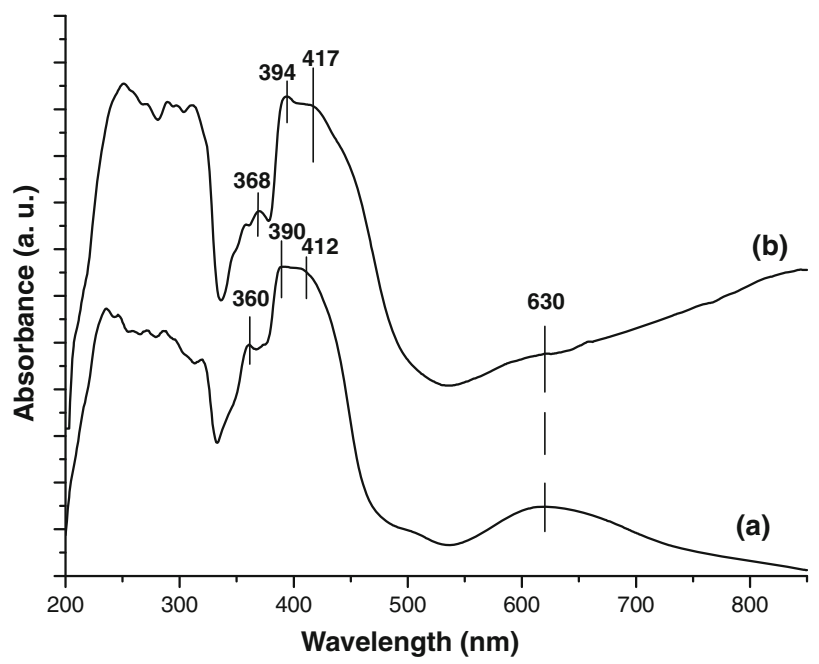

Fig. 5 UV-vis spectra of (a) VO(salen) complex (sample 14) and (b) Si-VO(salen) (sample 11)

The $\mathrm{N}_{2}$ adsorption-desorption isotherms and the corresponding $\mathrm{BJH}$ pore size distributions based on the desorption branch for the silica samples are shown in Figs. 6 and 7. The nitrogen isotherm of the untreated silica sample shows a sharp capillary condensation step at a relative pressure from 0.7 indicating a mesoporous structure of the silica with a uniform pore size distribution. Compared to the untreated silica sample, the aminopropylsilyl-functionalized silica and $\mathrm{Si}-\mathrm{VO}$ (salen) show a significant change in the $\mathrm{N}_{2}$ adsorption-desorption isotherm and the pore size distribution. A large decrease in BET surface area was observed on functionalization of modified silica, with a reduction in the pore diameter and pore volume, suggesting that $\mathrm{VO}$ (salen) complex is present inside the pores of the support material (see Table 1).

Catalytic activity

The above results and the usefulness of the optically active sulfoxides in the asymmetric synthesis of organic compounds prompted us to study the neat and the covalently anchored $\mathrm{VO}$ (Salen) complex in asymmetric sulfoxidation (Eq. 1).

The chemical and optical yields of sulfoxide were compared under several reaction conditions (Table 2). The asymmetric oxidation of methyl phenyl sulfide has been studied at a 2.0 oxidant/sulfide molar ratio. This showed that an increasing amount of oxidant improves the degree of enantiomeric excess significantly [38].

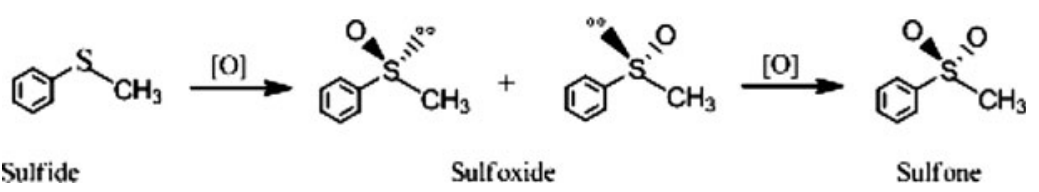




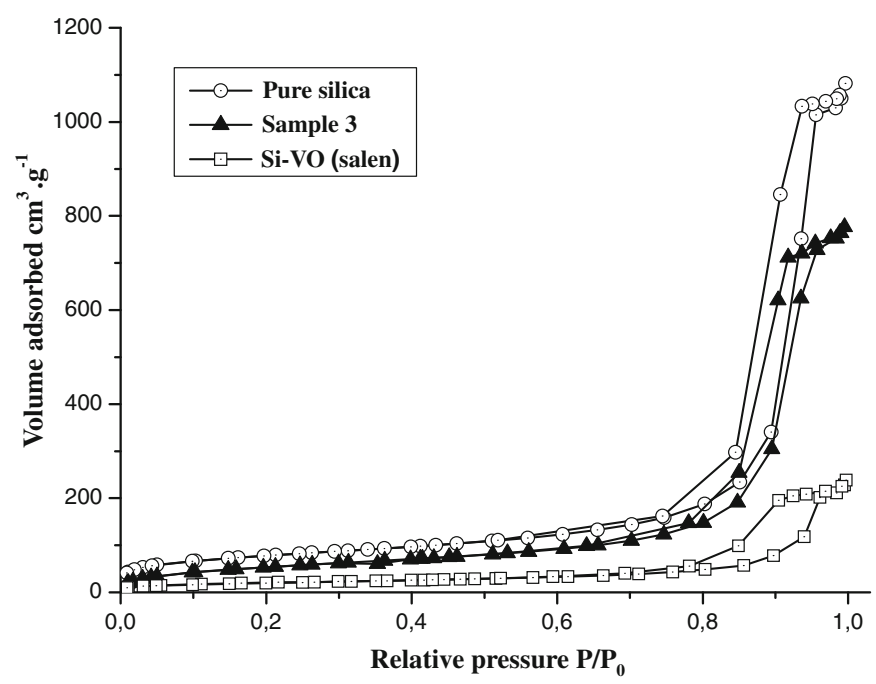

Fig. 6 The nitrogen adsorption-desorption isotherms of pure silica, sample 3 and $\mathrm{Si}-\mathrm{VO}$ (salen)

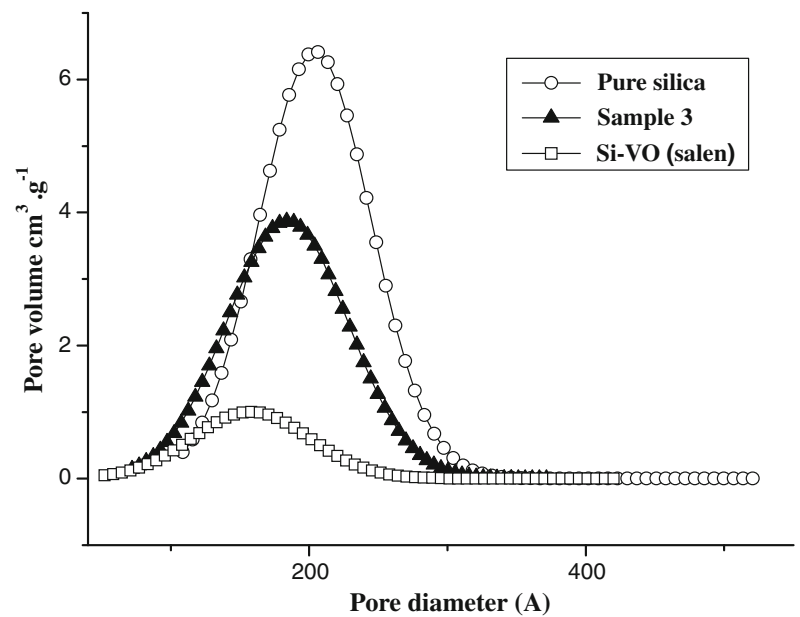

Fig. 7 BJH pore size distribution curve of pure silica, sample 3 and $\mathrm{Si}-\mathrm{VO}$ (salen)

Table 1 Results of textural properties of pure silica, aminopropylsilyl-functionalised silica (sample 3) and $\mathrm{Si}-\mathrm{VO}($ salen)

\begin{tabular}{llll}
\hline Compound & $\begin{array}{l}\text { BJH pore } \\
\text { diameter }(\AA)\end{array}$ & $\begin{array}{l}\text { Total pore } \\
\text { volume }\left(\mathrm{cm}^{3} \mathrm{~g}^{-1}\right)\end{array}$ & $\begin{array}{l}\text { BET surface } \\
\text { area }\left(\mathrm{m}^{2} \mathrm{~g}^{-1}\right)\end{array}$ \\
\hline Pure silica & 160 & 1.60 & 300 \\
Sample 3 & 148 & 1.12 & 195 \\
Si-VO(salen) & 137 & 0.33 & 74 \\
\hline
\end{tabular}


Table 2 Results obtained in the asymmetric oxidation of methylphenylsulfide

\begin{tabular}{|c|c|c|c|c|c|c|c|}
\hline Entry & Catalyst & Solvent & $\begin{array}{l}\text { Temperature } \\
(\mathrm{K})\end{array}$ & $\begin{array}{l}\text { Sulfide } \\
\text { conv }(\%)\end{array}$ & $\begin{array}{l}\text { Sulfoxide } \\
(\%)\end{array}$ & $\begin{array}{l}\text { Sulfone } \\
(\%)\end{array}$ & $\begin{array}{l}\mathrm{Ee} \\
(\%)^{\mathrm{t}}\end{array}$ \\
\hline 1 & $\mathrm{VO}$ (salen) & $\mathrm{CH}_{2} \mathrm{Cl}_{2}$ & 298 & No reaction & - & - & - \\
\hline 2 & $\mathrm{Si}-\mathrm{VO}($ salen $)$ & $\mathrm{CH}_{2} \mathrm{Cl}_{2}$ & 298 & 38 & 83 & 17 & 5 \\
\hline 3 & $\mathrm{Si}-\mathrm{VO}$ (salen) & Toluene & 298 & 15 & 16 & 84 & 2.5 \\
\hline 4 & $\mathrm{Si}-\mathrm{VO}($ salen $)$ & $\mathrm{CH}_{3} \mathrm{CN}$ & 298 & No reaction & - & - & - \\
\hline 5 & $\mathrm{Si}-\mathrm{VO}($ salen $)$ & $\mathrm{tBuOH}$ & 298 & No reaction & - & - & - \\
\hline 6 & Si-VO(salen) & $\mathrm{CH}_{2} \mathrm{Cl}_{2}$ & 273 & 31 & 91 & 9 & 8 \\
\hline 7 & $\mathrm{Si}-\mathrm{VO}($ salen$)$ & $\mathrm{CH}_{2} \mathrm{Cl}_{2}$ & 263 & 25 & 94 & 6 & 10 \\
\hline 8 & $\mathrm{Si}-\mathrm{VO}(\text { salen })^{\mathrm{a}}$ & $\mathrm{CH}_{2} \mathrm{Cl}_{2}$ & 263 & 20 & 79 & 21 & 4.5 \\
\hline
\end{tabular}

Reaction conditions: methyl phenyl sulfide, $2 \mathrm{mmol} ; 33 \mathrm{wt} \% \mathrm{H}_{2} \mathrm{O}_{2}$ aq., $4 \mathrm{mmol}$; catalyst, $0.2 \mathrm{mmol}$ as $\mathrm{V}$; and dry solvent, $10 \mathrm{~mL}$

a The reaction was carried with a recycled catalyst

b The e.e.s were determined from the ${ }^{1}$ H NMR spectrum in the presence of (S)-N-(3,5 dinitrobenzoyl)- $\alpha$ phenylamine as a chiral shift base

As it can be observed in Table 2, the covalently anchored complex gave, under the same reaction conditions (solvent, reaction temperature, etc.,) better conversion than the neat $\mathrm{VO}($ Salen) complex (entries 1 and 2). In reactions with metal Schiff base complexes in homogeneous medium, one often encounters catalyst deactivation due to the formation of oxo-bridged dimer complexes, which has been confirmed by spectroscopic studies using similar oxovanadium(IV) complexes [39].

The asymmetric oxidation of methyl phenyl sulfide was investigated in different solvents with $\mathrm{Si}-\mathrm{VO}$ (salen) as catalyst. The nature of the solvent was found to have a remarkable effect on the catalytic activity of $\mathrm{Si}-\mathrm{VO}$ (salen). In fact, no reaction was observed in $\mathrm{CH}_{3} \mathrm{CN}$ nor $t$-BuOH (entries 4 and 5). This can be explained by the deactivation of the catalyst due to the inhibitory effect of $\mathrm{CH}_{3} \mathrm{CN}$ or $\mathrm{tBuOH}$ via its strong adsorption on the solid catalyst.

In the presence of toluene (entry 3 ), the oxidation of sulfide leads to a decrease in the catalytic activity and in sulfoxide selectivity with a very low enantioselectivity of $2.5 \%$ ee. According to the study realized by Basset et al. [40] in the epoxidation of allylic alcohols, this result can be explained by the strong adsorption of toluene on the solid catalyst limiting the access of the reactants into the active sites.

Since toluene gave low activity and poor sulfoxide selectivity and both $t$ - $\mathrm{BuOH}$ and $\mathrm{CH}_{3} \mathrm{CN}$ led to inhibitory effects of the catalyst, the best choice seems $\mathrm{CH}_{2} \mathrm{Cl}_{2}$.

The reaction was also carried out at 0 and $-10^{\circ} \mathrm{C}$ using $\mathrm{Si}-\mathrm{VO}$ (salen) as catalyst and $\mathrm{CH}_{2} \mathrm{Cl}_{2}$ as solvent (entries 6 and 7). The decrease of the reaction temperature results in a decrease in the sulfide conversion with an increase in sulfoxide selectivity. The decrease in the sulfide conversion can be explained by the decrease of the oxidation reaction rate at low reaction temperature with the parallel increase in sulfoxide selectivity by the decrease of the rate of the oxidation of sulfoxide to sulfone. 
The same effect was observed in enantioselectivity and the sulfoxide selectivity when the reaction temperature was decreased. The enantiomeric excess increased from $5 \%$ at $25{ }^{\circ} \mathrm{C}$ to $8 \%$ at $0{ }^{\circ} \mathrm{C}$ and $10 \%$ at $-10{ }^{\circ} \mathrm{C}$. On the basis of this result, it is thought that the increase in sulfoxide selectivity with the decrease of the reaction temperature would improve the degree of enantiomeric excess.

The catalyst ( $\mathrm{Si}-\mathrm{VO}($ salen)) was separated after the reaction, washed and re-used for a second time (entry 8). A remarkable decrease in the sulfide conversion, sulfoxide selectivity and enantioselectivity was observed. This can be explained by the blocking of the pores either by inactive V-oxo species formed during the catalytic process [39] or by some other insoluble side reaction products which after several washings could not be removed from the materials.

\section{Conclusion}

The VO(salen) complex was immobilized on silica via a multi-grafting method. The formation and integrity of the complex have been confirmed by FT-IR, UV-Vis, using the neat complex as a reference. Immobilized VO(Salen) complex is efficient for the selective sulfide oxidation reaction, leading to a low but significant enantiomeric excess $(8-10 \%)$. Compared to the neat complex, the catalytic studies revealed that anchoring of $\mathrm{VO}($ Salen) complex on functionalized silica enhances the stability of $\mathrm{VO}($ Salen) complex during the oxidation reaction by elimination of inactive oxo-vanadium species.

Open Access This article is distributed under the terms of the Creative Commons Attribution Noncommercial License which permits any noncommercial use, distribution, and reproduction in any medium, provided the original author(s) and source are credited.

\section{References}

1. Beller M, Bolm C (eds) (1998) Transition metals for organic synthesis. Wiley-VCH, Weinheim, Germany

2. Jacobsen EN, Pfaltz A, Yamamoto H (eds) (1999) Comprehensive asymmetric catalysis. Springer, Berlin

3. Ojima I (ed) (2000) Catalytic asymmetric synthesis, 2nd edn. VCH Publisher, New York

4. Jacobsen EN, Larrow JF, Gao Y, Hong Y, Nie X, Zepp CM (1994) J Org Chem 59:1939

5. Pozzi G, Cinato F, Montanari F, Quici S (1998) J Chem Soc Chem Commun 877

6. Shyu H-L, Wei H-H, Lee G-H, Wang Y (2000) J Chem Soc Dalton Trans 915

7. Lee NH, Jacobsen EN (1991) Tetrahedron Lett 32:6533

8. Irie R, Noda K, Ito Y, Matsumoto N, Katsuki T (1990) Tetrahedron Lett 31:7345

9. Saito B, Katsuki T (2001) Tetrahedron Lett 42:3873

10. Nakajima K, Kojima K, Aoyama T, Fujita J (1986) Chem Lett 1483

11. Niimi T, Uchida T, Irie R, Katsuki T (2000) Tetrahedron Lett 41:3647

12. Nishikori H, Katsuki T (1996) Tetrahedron Lett 37:9245

13. Kantam ML, Bharathi B (1998) Catal Lett 55:235

14. Ernst S, Fuchs E, Yang X (2000) Microporous Mesoporous Mater 35-36:137

15. Ayala V, Corma A, Iglesias M, Rincón JA, Sánchez F (2004) J Catal 224:170

16. Song CE, Roh EJ, Yu BM, Chi DY, Kim SC, Lee KJ (2000) J Chem Soc Chem Commun 615

17. Smith K, Liu CH (2002) J Chem Soc Chem Commun 886 
18. Xiang S, Zhang Y, Xin Q, Li C (2002) J Chem Soc Chem Commun 2696

19. Bigi F, Moroni L, Maggi R, Sartori G (2002) J Chem Soc Chem Commun 716

20. Kureshy RI, Khan NH, Abdi SHR, Ahmad I, Singh S, Jasra RV (2004) J Catal 221:234

21. Dominguez I, Fornés V, Sabater MJ (2004) J Catal 228:92

22. Silva AR, Budarin V, Clark JH, de Castro B, Freire C (2005) Carbon 43:2096

23. Baleizão C, Gigante B, Garcia H, Corma A (2003) J Catal 215:199

24. Deshmukh MN, Dunach E, Juge S, Kagan HB (1984) Tetrahedron Lett 25:3467

25. Zamian JR, Dockal E, Castellano G, Oliva G (1995) Polyhedron 14:2411

26. Lopez J, Liang S, Bu XR (1998) Tetrahedron Lett 39:4199

27. Ueno K, Martel AE (1956) J Phys Chem 60:1270

28. Faniran JA, Patel KS, Bailar JC (1974) J Inorg Nucl Chem 36:1547

29. Bottino FA, Finocchiaro P, Libertini E (1988) J Coord Chem 16:341

30. Percy GC, Thornton J (1973) J Inorg Nucl Chem 35:2319

31. Patel KS, Kolawole GA (1982) J Coord Chem 11:231

32. Callahan KP, Durand PJ (1980) Inorg Chem 19:3211

33. Devi GS, Indrasenan P (1987) Inorg Chim Acta 133:157

34. Chatterjee D, Mitra A, Shephered RE (2004) Inorg Chim Acta 357:980

35. Pretsch E, Seibl J (1983) Tables of spectral data for structure determination of organic compounds. Springer-Verlag, Berlin

36. Salavati-Niasari M, Salimi Z, Bazarganipour M, Davar F (2009) Inorg Chim Acta 362:3715

37. Camblor MA, Corma A, Perez-Pariente J (1993) J Chem Soc Chem Commun 557

38. Piychen P, Kagan HB (1984) Tetrahedron Lett 43:3135

39. Joseph T, Srinivas D, Gopinath CS, Halligudi SB (2002) Catal Lett 83:209

40. Meunier D, de Mallmann A, Basset JM (2003) Top Catal 23:183 